UDC 316.245+304.3

LBC 60.5

\title{
IN-DEMAND BODY IN REPRESENTATIONS OF PUPILS ${ }^{1}$
}

\author{
Anatoly V. Merenkov \\ Ural Federal University named after the first President of Russia B.N. Yeltsin, \\ Yekaterinburg, Russian Federation
}

\begin{abstract}
The article considers the ideas of young people aged 16-17 about the requirements of modern society to the external characteristics of the body, internal qualities of a person on the basis of empirical research. The objectives of the study were to identify opinions about what requirements are imposed by modern society to the external characteristics of the male and female body at this age, what practices are used to make the body attractive to people around, representatives of the other sex. The opinions of those moral and aesthetic qualities, the presence of which provides the inner beauty of a person were pointed out. The author determines the influence of social networks, media personalities on the formation of the image of the body desired by young people. In 2019, 200 students of 10-11 grades of secondary schools in Ekaterinburg, which is a major industrial and cultural center of the country, were interviewed by a questionnaire method. Significant differences in the ideas of young people about what kind of body they consider to be in demand were found. According to respondents, the male body has fewer requirements than the female one. The main indicator of its outer attractiveness is the pronounced muscle mass created by regular sports activities. The inclusion of women in active labor, social activities did not lead to the approval of new ideas about her appearance. She, as before, should be attractive, regardless of what she does at work, at home, where she appears in public places. The main factors influencing the formation of ideas about the outer attractiveness of the male and female body were revealed: personal beliefs, social networks, images of media personalities. Men do not have a clearly expressed direction for constant self-improvement in order to construct themselves as healthy, with developed skills of mental activity, culturally communicative persons. Representatives of the female sex appreciate, much higher than the male, the qualities that determine the inner beauty of a person: mental abilities, the ability to behave correctly with different people, strong will, patience, responsibility. There is a danger of gender conflict intensifying in the future. Girls will have difficulties in finding partners corresponding to the level of development of their knowledge, skills, latitude of thought. They are more willing to actively participate in the social and economic and social and cultural development of a dynamically changing society.

Key words: body, in-demand body, stereotypes of male and female bodies, young people studying, outer beauty, qualities that determine the attractiveness of a person.
\end{abstract}

УДК $316.245+304.3$

ББК 60.5

\section{ВОСТРЕБОВАННОЕ ТЕЛО В ПРЕДСТАВЛЕНИЯХ УЧАЩИХСЯ ШКОЛ ${ }^{1}$}

\author{
Анатолий Васильевич Меренков \\ Уральский федеральный университет им. первого Президента России Б.Н. Ельцина, г. Екатеринбург, \\ Российская Федерация
}

Аннотация. В статье на материалах эмпирического исследования рассматриваются представления
молодых людей 16-17 лет о требованиях, предъявлемых современным обществом ко внешним характерис-
тикам тела, внутренним качествам человека. Исследование направлено на выявление мнений о том, какие
требования предъявляются современным обществом ко внешнему характеристикам мужского и женского
тела в этом возрасте, какие практики используются для того, чтобы тело стало привлекательным для окружа-
ющих людей, представителей другого пола. Выявлялось мнение о тех моральных, эстетических качествах,
наличие которых обеспечивает внутреннюю красоту человека. Определялось влияние социальных сетей,
медийных личностей на формирование образа желаемого молодыми людьми тела. В 2019 г. методом анкети- 
рования было опрошено 200 учащихся 10-11 классов общеобразовательных школ г. Екатеринбурга, являющегося крупным промышленным и культурным центром страны. Обнаружены существенные различия в представлениях молодых людей о том, какое тело они считают востребованным. По мнению респондентов, к мужскому телу предъявляется меньше требований, чем к женскому. Основным индикатором его внешней привлекательности является выраженная мышечная масса, создаваемая регулярными спортивными занятиями. Включение женщины в активную трудовую, общественную деятельности не привело к утверждению новых представлений о ее внешности. Она, как и прежде, должна быть привлекательной, независимо от того, чем занимается на работе, в быту, в каких общественных местах появляется. Выявились основные факторы, влияющие на формирование представлений о внешней привлекательности мужского и женского тела: личные убеждения, социальные сети, образы медийных личностей. У мужчин отсутствует явно выраженная установка на постоянное самосовершенствование с целью конструирования себя как здорового человека. Представители женского пола значительно выше ценят качества, определяющие внутреннюю красоту человека. Возникает опасность усиления в будущем гендерного конфликта. Они в большей мере готовы активно участвовать в социально-экономическом и социокультурном развитии динамично меняющегося общества.

Ключевые слова: тело, востребованное тело, стереотипы мужского и женского тела, учащаяся молодежь, внешняя красота, качества, определяющие привлекательность человека.

\section{Постановка проблемы}

Человеческое тело, его психофизические и социокультурные характеристики определяют возможности занятия различными видами деятельности, самореализацию и самоутверждение при взаимодействии с социальными субъектами. Во все времена люди стремились создать тело, которое позволяет успешно выполнить требования физического и умственного труда, обеспечить защиту от разных болезней, создать семью, осуществить воспроизводство следующего поколения. Формировалось востребованное в каждую историческую эпоху (в зависимости от условий жизни, социального статуса, гендерной принадлежности) тело [Гольман 2014; Siep 2003]. Культура, как система искусственно созданных предметов, норм, правил, отношений между людьми, усиливает или ослабляет действие природных факторов, определяющих возможности мужского и женского организма.

В течение многих веков, вплоть до второй половины XX в., когда началась автоматизация промышленного производства, утверждался образ мужественного мужчины, обладающего физической силой, ловкостью, стойкостью, умеющего принимать правильные решения в сложных ситуациях. Занятия охотой, обработка земли, военное дело требовали такого тела [Омельченко 2008].

Психофизические возможности, определяющие особое положение мужчины в производственной деятельности, материальном обеспечении семьи, возвышали его над жен- щиной. Он выбирал, в первую очередь по внешним характеристикам, ту, которая может стать женой, матерью детей, выступал в роли главы семьи, диктующего ее поведение с ним, бытовые обязанности, воспитание нового поколения. Утвердились стереотипы мужского тела, которое не только отличается заданными природой внешними признаками, но и особыми умственными способностями, определяющими воспроизводство гендерного неравенства в образовании, сферах трудовой и общественной деятельности, в отношениях между супругами.

В патриархальном обществе культура усиливает природное неравенство женщины с мужчиной. Иные физические способности, необходимость вынашивания ребенка, забота о нем в первые месяцы и годы жизни исключили ее из материального производства, которым занимаются представители сильного пола. Утвердилось представление о том, что женщине не требуется развивать умственные способности, поскольку ее домашний труд не связан с решением сложных задач, носит рутинный характер. Она во всем уступает мужчине [Weininger 2005]. Господствовал стереотип о двух разных (как по внешним, так и внутренним характеристикам) телах.

В условиях развития промышленного производства, когда недостаток рабочих рук привел к необходимости включить женщин в производительный труд, стали разрушаться веками существовавшие представления об особенностях и возможностях мужского и женского организма. Сформированные эгали- 
тарной культурой нормы стали ослаблять роль природных отличий представителей разных полов. Практика доказала, что женщины обладают такими же, как и мужчины, умственными способностями для занятий любыми видами научной, исследовательской, управленческой деятельности. Они успешно справляются с самыми сложными машинами и механизмами как на производстве, так и в быту. В то же время женщины сохраняют отличия в своем поведении, которые возникли и утвердились в прошлом [Aalten 1997; Turner 2008].

Устойчиво воспроизводится потребность быть внешне привлекательной. Это вызвано не только тем, что до сих пор сохраняется ведущая роль мужчины при выборе той, с кем он создает семью. Женщина знает, что ее внешний вид постоянно оценивается дома, в общественных местах, в организации, где она трудится, причем не только представителями другого пола, но и своего. Возникает необходимость поддержания различными способами положительной оценки фигуры, лица, походки. Многие мужчины этим не озабочены, самоутверждаясь достижениями в профессиональной деятельности, приобретенными материальными возможностями. С одной стороны, в современном обществе действуют схожие требования к женскому и мужскому телу, с другой стороны, сохраняются различия, влияющие на практики его конструирования [Клецина, Иоффе 2017].

Новое поколение с раннего детства включается в процесс освоения норм, которым должно соответствовать мужское и женское тело. У девочек вырабатывают навыки создания внешней привлекательности с помощью прически, красивой одежды, косметики. При воспитании мальчиков, как и прежде, на это обращается мало внимания. Такие характеристики их тела, как сила, ловкость, высокая подвижность, умение использовать простые инструменты в быту, уже не формируются путем включения в традиционный для мужчин домашний труд. Благоустроенное жилище, современная бытовая техника, использование специалистов при ее ремонте исключили необходимость выработки у всех мальчиков трудовых навыков, которые создают умелые руки, знающий методы использования простых орудий труда мозг. Спорт стал в наше время основным средством формирования тела будущих мужчин [Алкемайер 2006].
Такие качества, как развитые умственные способности, навыки культурного общения, умение заботиться о других людях, составляющие основу внутренней красоты человека, должны в одинаковой мере формироваться у детей обоего пола [Witz 2000]. Однако при воспитании девочек больше внимания обращается на формирование способностей, позволяющих в будущем создать благополучную семью, обеспечить равную с мужчинами конкурентоспособность на рынке труда [Задворнова 2014]. Вступая в подростковый возраст, девушки сталкиваются с тем, что им необходимо постоянно заниматься конструированием своей привлекательности [Shilling 2008]. Требования, которые предъявлялись к женщине в прошлом, связанные с ее внешностью, усилены установками на то, что она должна быть образованной, умной, общительной, работоспособной, заботливой женой, матерью, умелой домохозяйкой, не уступая мужчинам в профессиональной деятельности [Gambles, Lewis, Rapoport 2006]. Нужно постоянно создавать способное к такой всесторонней деятельности тело. Мужчина, как и прежде, освобожден от необходимости обязательно конструировать внешне привлекательное тело. До сих пор он имеет преимущества при трудоустройстве, карьерном продвижении.

В связи с этим актуальной проблемой становится изучение представлений молодых людей, у которых завершается в старших классах школы период первичной социализации, о том, какой по внешним и внутренним характеристикам человек востребован в наше время. Выявляется влияние семьи, школы, средств массовой информации, моды на конструирование внешней и внутренней красоты, определяющей самореализацию и самоутверждение современного человека во всех сфеpax повседневной жизнедеятельности.

\section{Методология и методы исследования}

Телесность человека в настоящее время стала предметом активного теоретического изучения [Азаренко 2006; Литвинова 2012; Turner 2008]. Проводятся эмпирические исследования, направленные на раскрытие способов конструирования тела, востребованного современной жизнью [Романовский 2006]. Особое 
внимание уделяется необходимости обеспечения единства внешней и внутренней красоты человека. Эта идея возникла еще в античное время в связи с формированием «культуры себя», направленной на развитие физических возможностей организма, его способностей к мыслительной работе [Foucault 1986, 51-78]. Возникают стереотипные представления о том, чем определяется привлекательность мужского и женского тела [Krueger et al. 2003]. Влияние стереотипов на отношения между индивидами и социальными общностями исследовал В. Липпманн, отмечая трудности их разрушения в процессе изменений условий жизнедеятельности человека [Lippmann 1922]. Особую роль в формировании представлений о востребованном теле играют гендерные стереотипы. Они детерминируют практики по формированию индивидами внешней привлекательности, развитию качеств, обеспечивающих внутреннюю красоту человека.

Потребности подростков в создании желаемого тела определяются особенностями их социализации [Young 2005]. Возникновение сексуального интереса ведет к тому, что особое внимание девочек и мальчиков уделяется способам конструирования внешней привлекательности. Девочки стремятся создать красивую фигуру с помощью занятий фитнесом, правильного питания [Куракин 2011, Wills et al. 2005]. Активно осваиваются техники макияжа, поведения, вызывающего повышенное внимание представителей другого пола. У мальчиков появляется желание заняться теми видами спорта, которые формируют типичную мужскую фигуру [Sczesny, Spreemann, Stahlberg 2006].

При этом ценность развития качеств, которые формируют внутреннюю красоту личности, снижается. Коммуникация в социальных сетях современных учащихся чаще всего не включает демонстрацию широкой образованности, глубоких знаний изучаемых в школе предметов [Викторова, Свертков 2013]. В то же время личностное и профессиональное самоопределение, активно осуществляемое в старших классах школы, побуждает заниматься развитием умственных способностей, коммуникативных навыков. Реализуется потребность создать тело, обладающее как внешней привлекательностью, так и качествами, определяющими внутреннюю красоту человека.

В 2019 г. нами было проведено социологическое исследование, целью которого являлось выявление представлений учащихся 16-17 лет о том, какое тело они хотели бы иметь, чтобы стать привлекательными для окружающих людей. Выяснялись мнения о внешних характеристиках мужского и женского тела, его способности к осуществлению социокультурных действий, обеспечивающих активную самореализацию и самоутверждение в современном обществе. Методом анкетирования было опрошено 200 учащихся 10-х и 11-х классов общеобразовательных школ. Среди респондентов $58 \%$ девушек и $42 \%$ юношей. Материальное положение их семей позволяет реализовать потребности детей в приобретении модной одежды, занятиях спортом, развитии интеллектуальных способностей.

\section{Результаты}

Прежде всего, выяснялось мнение о том, какое мужское и женское тело считается, по мнению респондентов, привлекательным.

Выявились существенные различия в представлениях молодых людей о том, какое тело они считают привлекательным (табл. 1).

Таблица 1

Внешние характеристики привлекательного мужского и женского т
\begin{tabular}{|l|c|c|c|c|}
\hline \multicolumn{1}{|c|}{ Показатели } & \multicolumn{2}{|c|}{ Мужское тело } & \multicolumn{2}{c|}{ Женское тело } \\
\cline { 2 - 6 } & мужчины & женщины & мужчины & женщины \\
\hline Спортивное тело & 28 & 45 & 19 & 26 \\
\hline Красивое лицо & 24 & 38 & 40 & 47 \\
\hline Здоровое тело & 22 & 35 & 18 & 29 \\
\hline Сильное тело & 18 & 28 & 0 & 0 \\
\hline Красивая фигура & 17 & 28 & 35 & 41 \\
\hline Стройное тело & 15 & 15 & 29 & 24 \\
\hline Подвижное & 10 & 12 & 6 & 11 \\
\hline Красивая улыбка & 9 & 33 & 3 & 2 \\
\hline Красивая походка & 3 & 11 & 0 & 0 \\
\hline
\end{tabular}


Прежде всего, обращает на себя внимание тот факт, что девушек оценивают по ограниченному количеству параметров. Сказываются, на наш взгляд, стереотипы восприятия женского тела, которые формировались веками и сохраняются до нашего времени. Сильное женское тело не востребовано природой, и культура не ориентирована на его создание. Отсутствовала необходимость участия женщин в охоте на хищников, военных действиях. Только в борьбе за равенство с мужчинами они в XX в. добились права участвовать в соревнованиях по тяжелой атлетике, хоккею, боксу, управлять техникой, требующей значительных физических усилий. Однако образ «слабой женщины», созданной не для тяжелой работы, воспроизводится в качестве устойчивого стереотипа у нового поколения.

Причиной того, что респонденты не отметили значимость походки женщины при восприятии ее привлекательности, заключается, видимо, в том, что веками существовала практика закрытия женских ног длинным платьем. Только в середине прошлого века появилась мода на короткую юбку. Следует отметить, что молодые люди не обращают внимания на улыбку при оценке облика девушек. Более важным является восприятие пропорций лица, его своеобразия, формирующее представление о нем, как о красивом. Являясь той частью тела, которая всегда открыта, лицо постоянно оценивается с точки зрения своей привлекательности. Уже в 5-6 лет девочки начинают сравнивать свое лицо с тем, которое у сверстниц. В подростковом возрасте они осваивают техники ухода за лицом, стремясь сделать его красивым. Девушки подражают известным медийным женщинам, образам, созданным художниками, фотографами. Недовольство своим лицом нередко ведет к появлению комплекса неполноценности, от которого женщина страдает в течение всей жизни, что побуждает использовать пластическую хирургию для коррекции губ, носа.

Исследование показало, что при оценке внешней привлекательности тела воспроизводятся господствующие в настоящее время стереотипы восприятия фигуры. Люди нередко сначала обращают внимание на нее, а потом на лицо женщины. Причиной является то, природа наградила женщину особой фигурой, чтобы подчеркнуть ее отличия от мужчины. Культура отдельных народов под влиянием религиозных представлений о том, как должна выглядеть женщина, ограничивает демонстрацию фигуры с помощью одежды, полностью или частично ее скрывающей. Фигура рассматривается как самый сильный фактор возникновения у мужчин сексуальных желаний. Остановить их будто бы можно, ограничивая видимые части тела. В XX в. под влиянием сексуальной революции появилась одежда, которая специально направлена на усиление сексуальной привлекательности женщины, подчеркивая достоинства ее фигуры.

Основным показателем ее несоответствия утвердившимся нормам стала полнота, искажающая пропорции тела. Девочками подросткового возраста она воспринимается как основной источник негативных переживаний по поводу внешности. Культ здоровой диеты активно утверждается в их сознании, что способствует улучшению женского здоровья. Оно рассматривается как индикатор привлекательности 29 \% девушек и 18 \% юношей. Следует отметить, что представители женского пола предъявляют более высокие требования к своему внешнему виду, чем те мужчины, которым они хотят понравиться.

Критерии красивого мужского тела всегда были иными. Веками формировалось представление о том, что мужчина должен выглядеть сильным, с развитым плечевым поясом, стройным, подвижным. Изменения в труде на промышленном производстве, в домашней работе, произошедшие в результате внедрения новой техники, привели к тому, что повседневная жизнь не требует сильного мужского тела. Однако стереотип прежнего его вида вызвал моду среди как молодых мужчин, так и среднего возраста, на занятия с тяжестями, разными видами борьбы, бокса в спортивных центрах.

Выделены основные индикаторы привлекательного мужского тела: оно сконструировано спортом, отличается накаченными мышцами, развитой грудной клеткой. Такое тело в первую очередь нравится девушкам, в подсознании которых сохраняются архетипы традиционного облика тех, кто их должен защищать при возникновении какой-либо опасности. Ими выше по сравнению с юношами це- 
нится здоровое, сильное мужское тело. Обращает внимание то, что каждая третья опрошенная выделяет красивую улыбку у мужчин, которые вызывают симпатию. Ее ценность утвердилась в результате формирования средствами массовой информации, журналами мод особого образа привлекательного мужчины. Он должен быть стройным, со спортивной фигурой и обязательно улыбаться, вызывая доверие, ощущение готовности заботиться о той, кто с ним будет рядом. В прошлом мужчины, если судить по картинам художников, выглядели серьезными, нередко с суровыми лицами.

Выявились основные факторы, влияющие на формирование представлений о внешней привлекательности мужского и женского тела. Среди девушек 49 \% заявили, что их мнение определяется личными убеждениями в том, какой человек может считаться красивым. В подростковом возрасте в процессе формирования представлений о своей внешности, степени ее соответствия определенным образцам возникают устойчивые критерии привлекательного лица, фигуры. При этом не фиксируется внимание на том, чье мнение повлияло на становление собственной позиции. Возникает иллюзия самостоятельного определения показателей прекрасного и безобразного, желаемого и отвергаемого. Среди юношей, менее озабоченных своей внешностью, 33 \% отмечают наличие личных убеждений о том, какого человека можно считать внешне красивым. Также среди девушек в два раза больше, чем среди юношей, тех, чье мнение возникло под влиянием желания постоянно совершенствовать себя: соответственно $25 \%$ и $13 \%$. Представители женского пола осознают, что в течение всей жизни им придется заниматься конструирова- нием своей внешности. К этому 8 \% опрошенных побуждает недовольство своими природными данными. Среди представителей мужского пола таких не оказалось.

Респонденты указали влияние социальных сетей на формирование образа привлекательного человека. Среди девушек $21 \%$ отметили этот фактор, а среди юношей - $13 \%$. В равной степени те и другие (12\%) указали на влияние человека, который им очень нравится. Примерно столько же фиксируют воздействие образов красивых людей в журналах, на телевидении.

Красота личности определяется не только внешними характеристиками. В процессе общения с разными людьми, чтения художественной литературы, просмотра кинофильмов, дружеского общения формируется представление о том, какие качества человека делают его привлекательным. Создается образ внутренней красоты, которая нередко оказывается более значимой, чем внешняя. Исследование выявило мнение молодых людей о том, какие личностные характеристики делают человека привлекательным.

Как и при оценке внешних показателей привлекательности человека, мнения о внутренних ее индикаторах у юношей и девушек существенно различаются (табл. 2). С одной стороны, сама иерархия ценностей оказывается примерно одинаковой, кроме оценки доброжелательности и оптимизма. С другой стороны, представители женского пола значительно выше ценят все качества, определяющие внутреннюю красоту человека. Видимо, у определенной части представителей мужского пола существует убеждение, что им не нужно постоянно совершенствовать навыки мыслительной деятельности, умение

Внутренние характеристики привлекательного человека, \%

\begin{tabular}{|l|c|c|}
\hline \multicolumn{1}{|c|}{ Показатели } & Мужчины & Женщины \\
\hline Развитые умственные способности & 33 & 47 \\
\hline Уважительное отношение к людям & 29 & 46 \\
\hline Сильная воля, терпение & 28 & 36 \\
\hline Доброжелательность & 26 & 47 \\
\hline Внутреннее спокойствие & 24 & 27 \\
\hline Общительность & 21 & 25 \\
\hline Оптимизм & 18 & 27 \\
\hline Ответственность & 17 & 23 \\
\hline Высокая работоспособность & 8 & 3 \\
\hline
\end{tabular}


проявлять доброжелательность, уважительное отношение к людям. Даже развитие воли, терпения не рассматривается как важная задача личностного роста. Однако без этих качеств достигнуть каких-либо значительных успехов в профессиональной, общественной деятельности невозможно.

Обращает внимание то, что ценность ума, соблюдение моральных норм, определяющих общение с разными людьми, отмечается только половиной опрошенных. Требовательность к себе, прежде всего ответственность, значимы для незначительной части респондентов. Крайне низка оценка роли высокой работоспособности в становлении внутренней красоты личности. Однако это качество во все времена считалось главным при выработке представлений о том, кого следует считать подготовленным для трудовой, семейной жизни. Низкая включенность подростков в домашний труд, не в полной мере развитые навыки постоянной умственной деятельности ведут к тому, что высокая работоспособность не рассматривается ими как показатель привлекательности человека. Будущая профессиональная деятельность, семейная жизнь потребует от них переоценки роли этого качества в процессе конструирования востребованной социумом личности.

Особую роль внешняя и внутренняя красота играет при реализации потребности понравиться человеку, вызывающему влечение, влюбленность. Свободный выбор будущего супруга / супруги осуществляется на основе любви, возникающей, когда внешность, личностные качества воспринимаются как привлекательные. В результате исследования были выявлены установки юношей и девушек на конструирование желаемого тела, когда хочется понравиться представителю другого пола (табл. 3).
Респонденты придерживаются единого мнения о том, что в этом случае в первую очередь следует развивать ум, обогащая его новыми знаниями. Так считают $18 \%$ представителей мужского пола и $19 \%$ - женского. $15 \%$ опрошенных займутся совершенствованием коммуникативных навыков, демонстрируя свой кругозор, рассказывая об увлечениях, которые могут стать общими. Утверждение себя как привлекательного человека с помощью внутренней культуры для молодых людей важнее, чем внешность, характеристики которой изменить не всегда возможно, так как они зависят от природы. Однако такие попытки все-таки будут предприниматься для того, чтобы, во-первых, как считают 17 \% опрошенных того и другого пола, сделать свою фигуру привлекательной. Для достижения этой цели они будут заниматься спортом, одновременно решая задачу улучшения своего здоровья. Во-вторых, 13 \% юношей и $17 \%$ девушек попытаются как-то изменить свое лицо.

В то же время $18 \%$ считают, что ничего менять в себе не станут, так как, по мнению $5 \%$ представителей мужского пола и $20 \%$ - женского, следует этим заниматься, когда обнаруживаешь отдельные недостатки, а не для того, чтобы понравиться другим. Сказывается ориентация на независимое от мнения окружающих поведение при общении с представителями другого пола.

Желание сделать себя более привлекательным человеком для разных людей в общественных местах, совместной учебной, трудовой деятельности высказали 94 \% респондентов.

В 16-17 лет хочется быть привлекательным как по внешним индикаторам, так и внутренним, которые определяются культурой мышления, формируемой приобретением востребованных в молодежной среде знаний.

Таблииа 3

Способы повышения привлекательности, \%

\begin{tabular}{|l|c|c|}
\hline \multicolumn{1}{|c|}{ Показатели } & Мужчины & Женщины \\
\hline Самообразование & 33 & 45 \\
\hline Занятие спортом, фитнесом & 30 & 43 \\
\hline Развитие коммуникативных навыков & 21 & 20 \\
\hline Приобретение красивой одежды & 19 & 23 \\
\hline Укрепление здоровья & 18 & 28 \\
\hline Правильное питание & 15 & 32 \\
\hline Татуировки, проколы & 3 & 5 \\
\hline Косметические средства & 1 & 22 \\
\hline
\end{tabular}


Однако ориентации на саморазвитие у представителей мужского пола сформированы в меньшей степени, чем у женского. Последние готовы активно заниматься самообразованием, спортом, чтобы сделать себя привлекательными во всех отношениях. У них значительно выше по сравнению с юношами ориентация на укрепление здоровья, в частности, с помощью правильного питания. При этом обучение в гимназии, лицее или в общеобразовательной школе не оказывают значимого влияния на содержание представлений учащихся 16-17 лет о внешней и внутренней красоте человека. Гендерные различия в уровне сформированности ценностей постоянной заботы о себе, готовности к самостоятельному развитию психофизических и социокультурных характеристик личности весьма значительны.

\section{Выводы}

Исследование показало, что у учащейся молодежи существуют разные представления о востребованном современным обществом мужском и женском теле. Требования к мужскому претерпевают существенные изменения по сравнению с теми, которые предъявляются к женскому. Основной причиной является освобождение представителей сильного пола от тяжелого физического труда на производстве, в быту. Включение женщины в активную трудовую, общественную деятельности не привело к утверждению новых представлений о ее внешности. Она, как и прежде, должна быть привлекательной, независимо от того, чем занимается на работе и в быту, в каких общественных местах появляется.

Исследование показало, что в системе первичной социализации учащейся молодежи не утвердились равные требования к активному развитию мужчинами и женщинами внешней и внутренней красоты. Девушки предъявляют более высокие требования к своему внешнему виду, чем юноши. У них отсутствует явно выраженная установка на постоянное самосовершенствование с целью конструирования своего тела как здорового, обладающего развитыми навыками мыслительной деятельности, культурного общения с разными людьми, волей, ответственностью за свои поступки. В будущем при создании семьи возникает угроза усиления гендерного конфликта. У девушек возникнут трудности при поиске партнеров, соответствующих уровню развития их знаний, умений, широте кругозора. Они в большей мере готовы, чем мужчины, активно участвовать в социально-экономическом и социокультурном развитии динамично меняющегося общества.

\section{ПРИМЕЧАНИЕ}

${ }^{1}$ Работа выполнена при поддержке гранта Российского фонда фундаментальных исследований (РФФИ), проект № 18-011-00150/19 «Социальные практики конструирования востребованного человеческого тела: состояние и тенденции».

The study was conducted with the financial support of RFBR, project no. 18-011-00150/19 "Social practices of constructing in-demand human body: situation and tendencies".

\section{СПИСОК ЛИТЕРАТУРЫ}

Азаренко 2006 - Азаренко С.A. Сообщество тела. М.: Академ. проект, 2006.

Алкемайер 2006 - Алкемайер T. Социология спорта. Телесные практики субъективации и самоинсценировки // Логос. 2006. № 3. С. 141-146.

Викторова, Свертков 2013 - Викторова А.С., Свертков И.А. Социальные сети и молодежь // Территория науки. 2013. № 3. С. 5-7.

Гольман 2014 - Гольман Е.А. Развитие представлений о телесных практиках в социальной науке // Социологические исследования. 2014. № 10. C. 127-136.

Задворнова 2014 - Задворнова Ю.С. Дифференциация домашнего труда в российской семье: гендерные стереотипы и современные тенденции // Женщина в российском обществе. 2014. № 1. C. 51-58.

Клецина, Иоффе 2017 - Клецина И.С., Иоффе Е.В. Гендерные нормы как социально-психологический феномен. М.: Проспект, 2017.

Куракин 2011-Куракин Д. Модели тела в современном популярном и экспертном дискурсе: к культурсоциологической перспективе анализа // Социологическое обозрение. 2011. № 10 (1-2). C. 56-74.

Литвинова 2012 - Литвинова Т.А. Тело и телесность: содержание понятий и основные подходы к изучению // Вестник Тверского государственного университета. Серия: Философия. 2012. № 4. С. 204-213. 
Омельченко 2008 - Омельченко Е.Л. Культурная география мужских тел: современный путеводитель // В тени тела. Ульяновск: Ульян. гос. ун-т, 2008. С. $17-45$

Романовский 2006 - Романовский Н.В. Тело человека - новые горизонты социального познания // Социологические исследования. 2006. № 4. C. 16-25.

Aalten 1997-Aalten A. Performing the body, creating culture // European Journal of Women's Studies. 1997. Vol. 4, № 2. P. 38-47.

Foucault 1986-Foucault M. The History of Sexuality, Vol. 3: The Care of the Self. N.Y.: Pantheon books, 1986 .

Gambles, Lewis, Rapoport 2006 - Gambles R., Lewis $S$., Rapoport R. The Myth of Work - Life Balance: the Challenge of Our Time for Men, Women and Societies. Chichester: John Wiley \& Sons, 2006.

Krueger et al. 2003 -Krueger J.I., Hasman J.F., Acevedo $M$., Villano P. Perceptions of trait typicality in gender stereotypes: Examining the role of attribution and categorization processes. Personality \& Social Psychology Bulletin. 2003. № 29 (1). P. 108-116.

Lippmann 1922 - Lippmann W. Public Opinion. New York: Harcourt-Brace, 1922.

Sczesny, Spreemann, Stahlberg 2006 - Sczesny S., Spreemann S., Stahlberg D. Masculine = Competent? Physical appearance and sex as sources of gender-stereotypic attributions // Swiss Journal of Psychology. 2006. № 65. P. 15-23.

Shilling 2008 - Shilling C. Foreword: Body pedagogics, society and schooling // Education, Disordered Eating and Obesity Discourse: Fat fabrications. L.: Routledge. P. IX-XV.

Siep 2003 - Siep L. Normative aspects of the human body // Journal of Medicine and Philosophy. 2003. № 28 (2). P. 171-185.

Turner 2008 - Turner B.S. The Body and Society: Explorations in Social Theory. $3^{\text {rd }}$ ed. L.: SAGE Publications Ltd, 2008.

Young 2005 - Young I.M. Female Body Experience: "Throwing Like a Girl" and Other Essays. Oxford; N.Y.: Oxford University Press, 2005.

Weininger 2005 - Weininger O. Sex and Character: An Investigation of Fundamental Principles. Bloomington Indianapolis: Indiana University Press, 2005.

Wills et al. 2005 - Wills W.J., Backett-Milburn K., Gregory S. \& Lawton J. The influence of the secondary school setting on the food practices of young teenagers from disadvantaged backgrounds in Scotland // Health Education Research. 2005. Vol. 4. P. 458-465. DOI: 10.1093/ her/cyg132.
Witz 2000 - Witz A. Whose Body Matters? Feminist Sociology and the Corporeal Turn in Sociology and Feminism // Body and Society. 2000. № 6 (2). P. 1-24.

\section{REFERENCES}

Azarenko S.A., 2006. Body community. Moscow, Academic project.

Alkemajer T., 2006. Sociology of sports. Body practices of subjectivization and self-depiction. Logos, no. 3, pp. 141-146.

Viktorova A.S., Svertkov I.A., 2013. Social networks and youth. Territorija nauki, no. 3, pp. 5-7.

Gol'man E.A., 2014. The development of ideas about bodily practices in social science. Sociologicheskie issledovanija, no.10, pp. 127-136.

Zadvornova I.S., 2014. Differentiation of domestic labour in the family: gender stereotypes and current trends. Women in Russian society, no. 1, pp. 51-58.

Kletsina I.S., Ioffe E.V., 2017. Gender norms as sociopsychological phenomenon. Moscow, Prospekt.

Kurakin D., 2011. Body models in modern popular and expert discourse: to the cultural-sociological perspective of analysis. Sociologicheskoe obozrenie, no. 10 (1-2), pp. 56-74.

Litvinova T.A., 2012. Body and body: the content of concepts and basic approaches to the study. Bulletin of Tver State University. Series: Philosophy, no. 4, pp. 204-213.

Omel'chenko E.L., 2008. Cultural geography of male bodies: a modern guide. In the shadow of the body, Ul'janovsk, Ul'janovsk University.

Romanovskij N.V., 2006. The human body is a new horizon of social knowledge. Sociologicheskie issledovanija, no. 4, pp. 16-25.

Aalten A., 1997. Performing the body, creating culture. European Journal of Women's Studies, vol. 4, no. 2, pp. 38-47.

Foucault M., 1986. The History of Sexuality. Vol. 3: The Care of the Self. New York, Pantheon books.

Gambles R., Lewis S., Rapoport R., 2006. The Myth of Work-Life Balance: the Challenge of Our Time for Men, Women and Societies. Chichester, John Wiley \& Sons.

Krueger J.I., Hasman J.F., Acevedo M., Villano P., 2003. Perceptions of trait typicality in gender stereotypes: Examining the role of attribution and categorization processes. Personality \& Social Psychology Bulletin, pp.108-116.

Lippmann W., 1922. Public Opinion. New York, Harcourt-Brace.

SczesnyS., Spreemann S., Stahlberg D., 2006. Masculine = Competent? Physical appearance and sex as 
sources of gender-stereotypic attributions. Swiss Journal of Psychology, pp. 15-23.

Shilling C., 2008. Body pedagogics, society and schooling. Education, Disordered, Eating and Obesity Discourse. London, Routledge, pp. IX-XV.

Siep L., 2003. Normative aspects of the human body. Journal of Medicine and Philosophy, no. 28 (2), pp. 171-185.

Turner B.S., 2008. The Body and Society: Explorations in Social Theory. $3^{\text {rd }}$ ed. London, SAGE Publications Ltd.

Young I.M., 2005. Female Body Experience: "Throwing Like a Girl" and Other Essays. Oxford; New York, Oxford University Press.
Weininger O., 2005. Sex and Character: An Investigation of Fundamental Principles. Bloomington Indianapolis, Indiana University Press.

Wills W.J., Backett-Milburn K., Gregory S., Lawton J., 2005. The influence of the secondary school setting on the food practices of young teenagers from disadvantaged backgrounds in Scotland. Health Education Research, vol. 4, pp. 458-465.

Witz A., 2000. Whose Body Matters? Feminist Sociology and the Corporeal Turn in Sociology and Feminism. Body and Society, no. 6 (2), pp. 1-24.

\section{Information about the Author}

Anatoly V. Merenkov, Doctor of Sciences (Philosophy), Professor, Head of the Department of Applied Sociology, Ural Federal University named after the First President of Russia B.N. Yeltsin, Mira St., 19, 620009 Yekaterinburg, Russian Federation, anatoly.mer@gmail.com, https://orcid.org/0000-0001-5900-0863

\section{Информация об авторе}

Анатолий Васильевич Меренков, доктор философских наук, профессор, заведующий кафедрой прикладной социологии, Уральский федеральный университет им. первого Президента России Б.Н. Ельцина, ул. Мира, 19, 620009 г. Екатеринбург, Российская Федерация, anatoly.mer@gmail.com, https://orcid.org/0000-0001-5900-0863 